for the understanding of the complexities of research into this particular form of applied science. Analysis of the results must be the work of specialists rather than the patient calculation of a single individual as it was in the pioneer days of Sir Charles Parsons. Furthermore, whole groups of firms are co-operating nowadays in research which has as its object the maintenance of the supremacy of Great Britain in marine engineering.

\section{MEDICINE IN 1850}

A NEW exhibition of "Medicine in 1850" was opened at the Wellcome Historical Medical Museum, 28 Portman Square, London, W.1, on May 30. There was present a distinguished company of about seventy guests. The address at the opening ceremony was given by Prof. Henry E. Sigerist, until recently professor of the history of medicine and director of the Institute of the History of Medicine at Johns Hopkins University, Baltimore. In intro. ducing Prof. Sigerist, the director of the Museum, Dr. Ashworth Underwood, mentioned that the exhibition had been planned to give an indication of the state of medicine and the medical sciences in the midyears of the nineteenth century, a departure point from which so much had happened in the last hundred years. Prof. Sigerist in his address said that he had known the work of the Museum for many years, and had visited it on many occasions. He remarked that the Museum and its library constitute the greatest institution of this type anywhere in the world. $\mathrm{He}$ said that he expressed this conviction not only as a result of his experience in the teaching of the history of medicine at Leipzig and at Baltimore, but also from his wide travels all over the world. Prof. Sigerist also emphasized the fact that while important old books tend on the whole to be preserved somewhere, there is every likelihood that instruments and appliances will be used for other purposes. The great national museums of various countries have only a few such objects, whereas the Wellcome Museum has a rich store of all instruments and appliances of that kind. With its library it is a unique institution for research and educational purposes. Prof. Sigerist referred fittingly to the exhibits in the present exhibition, and said that it would be a source of inspiration and instruction not only to scholars and medical men, but also to all groups of the public from the child to the lay adult. He congratulated Dr. Underwood and his colleagues on a fine performance. Lord Webb-Johnson, a former president of the Royal College of Surgeons, and Mr. L. C. Bullock, deputy chairman of the Wellcome Trustees, also spoke.

The new exhibition is set up in the ground-floor galleries of the Museum. It deals first with the basic sciences (physies, chemistry, biology, anatomy and embryology, physiology and pathology), and then covers the history of the introduction of diagnostic instruments, such as the stethoscope, laryngoscope, and clinical thermometer. There follows then a large section devoted to clinical medicine, with special emphasis on diseases of the heart, circulation, ductless glands, and nervous diseases. This section is succeeded by exhibits on pharmacology and specialized methods of treatment. The final sections deal with the history of infectious diseases and public health.
In the field of the basic sciences, reference is made in the section on physics to the work of the great pioneers of the early nineteenth century, and among the exhibits is an original voltaic pile, probably used by Volta himself. The section on chemistry deals with the period when Dalton, Berzelius and Avogadro had already laid the modern foundations of inorganic chemistry, and organic chemistry, following on the eventful work of Wöhler, had been progressing under the guidance of Chevreul and Gerhardt. There are shown a number of original specimens prepared and labelled by Chevreul, and other original exhibits. Both in organic chemistry and physiological chemistry Justus von Liebig, of Giessen, was one of the great pioneers. In the chemical laboratory of to-day he is still remembered for his condenser and his combustion tube, and his "Animal Chemistry" was the first original treatise on physiological chemistry. Liebig was a very good subject for the portrait painter, and in this exhibition is shown a fine portrait of Liebig at the age of forty-two; the picture, which is signed and dated 1845 , is by C. F. W. Trautschold, and is obviously painted by him.

The section on biology covers the period when Cuvier's influence, though still paramount at first, was beginning to be merged in that of rising leaders. There is a fine case of preparations of the parts of the ear of a horse, prepared and labelled by Cuvier himself. Also shown are some of the works of a great pioneer of protozoology-C. G. Ehrenberg-in the form of three of the magnificent plates (of $A m c e b a$, Paramecium, and certain bacteria) from his work on the Infusoria. Art lovers will also be interested in the two etchings by $\mathbf{P}$. A. Rajon after the portrait of Darwin by Ouless. The first state of the etching is a specially interesting and vigorous work.

The physiological section is large and can be dealt with here only briefly. Very interesting is some of the original apparatus made and used by Galvani, whose influence in 1850 was extending rapidly as a result of the work of Duchenne of Boulogne, Du Bois Reymond and others. In the sphere of the circulation, especially important work was done by Chauveau and Marey, together and independently. Their apparatus for charting automatically the action of the heart and the large blood vessels is dealt with fully, and there is also showri a fine commemorative plaque to Chauveau. Claude Bernard, Bowman, Lord Lister and others are also dealt with under this heading. The anatomical section is notable for some fine models of the brain and other parts. To be noted also is the first edition of Gray's "Anatomy", published in 1858. Many of the plates in this work are practically unchanged, even in the most recent (the thirtieth) edition.

In the section on the microscope and histology, there is a fine series of eight original daguerreotypephotomicrographs made for Donné's "Atlas" in $\mathbf{1 8 4 4}$ by Léon Foucault. These daguerreotypes are in a remarkable state of preservation, and it is good to know that they are safely preserved in the Wellcome Museum. In the section on pathology three very notable exhibits are the works by Hope (1834), Sir Robert Carswell (1838) of University College, London, and Jean Cruveilhier (1829-42). The latter is certainly one of the most sumptuous of all illustrated medical books.

The section on the stethoscope gives an excellent review of the development of this instrument, and one of the exhibits is an original Laennec stethoscope, presented by Laënnec himself to a friend. The history 
of the clinical thermometer is dealt with in an illuminating way, and the instruments of Hunter, Aitken and Allbutt are specially noteworthy.

The great medical classics of the period are shown in the section on clinical medicine, including the works of Addison and Bright. Also shown are some of the original series of coloured prints of pathological subjects made for Bright's great work. There is a fine commemorative plaque to Charcot, and some original apparatus used by Duchenne.

Space does not permit of further descriptions of individual items, but it may be said that the section on blood-letting will repay careful study, and that the section on blood-transfusion lays due emphasis on the work of Blundell and of Aveling. The exhibits dealing with infectious diseases include the pioneer works of Stewart, Murchison, Snow and others; and the section on public health exhibits a number of scarce prints illustrative of the hygienic conditions of the time.

This fine exhibition is full of interest and instruction for the scientific worker and layman alike, and the staff of the Museum are to be congratulated on the results. A full descriptive and bibliographical catalogue has just been published by the Oxford University Press*, and is obtainable at the Museum or from the Press.

* Catalogue of an Exhibition illustrating Medicine in 1850. Published for the Trustees of the Wellcome Historical Medical Museum. Pp. 64. (Oxford University Press, 1950.) 3s. net.

\section{RESEARCH IN THE UNIVERSITY OF BIRMINGHAM}

\section{ANNUAL REPORT FOR 1948-49}

$\mathrm{T}$ HE twentieth annual report of the Joint Standing Committee for Research of the University of Birmingham covers the session 1948-49*, and the summaries included under the departmental sections give a comprehensive survey of progress made in the various fields during the year. To these summaries are appended departmental lists of papers published during the year and of titles of theses approved for higher degrees. Only publications which can properly be regarded as contributions to original knowledge are included.

In the Department of Physics the most ambitious undertaking was the construction of a synchrotron for the acceleration of protons to energies corresponding to about 1,200,000 volts; good progress was made in this undertaking. The cyclotron was out of operation for alterations during much of the year. The research programme benefited greatly from the arrangements made for universities to obtain radioactive materials and electronic equipment from government sources. In the Department of Chemistry the balance of work between the physical and the organic side was much more even, much of the former being concerned with the chemistry of synthetic high-polymers and of the latter with the chemistry of natural high-polymers such as cellulose and starch. Work on synthetic high polymers comprised the investigation of the mechanism of synthesis with the view of putting the whole matter on a sound quantitative and absolute basis. Further researches were

* Uniyersity of Birmingham: Joint Standing Committee for Research. Twentieth Annual Report, Session 1948-49. Pp. 81. (Birmingham: The University, 1950.) carried out to elucidate the mechanism of heterogeneous processes such as the thermal decomposition of crystals of nickel formate, and work on the determination of molecular structure by X-ray diffraction continued, as well as on the new organic fluorine compounds. Help was given to the development of dextrose blood-plasma substitute, the group working on chemistry in relation to tuberculosis continued work on the separation of nucleic acid and carbohydrate components from cells which might have a preventive action against the disease, and a vigorous section was established for research on analytical chemistry.

Work continued in the Department of Zoology on the mechanism of transplantation immunity in animals, and further support for the hypothesis that certain virus-like cytoplasmic factors may be of endogenous origin was obtained from immunological and other studies on 'infective' agents responsible for natural skin coloration in mammals. A study of wound healing was commenced and work completed on the differential host preferences of the hymenopterous insect Cephalonomia. In the Department of Botany research on salt relations of plant cells indicated that the antagonism between ions in their absorption concerns both phases in absorption. Symptoms similar to those resulting from ion deficiency noted on land treated with sewage sludge contaminated with industrial waste were attributed to toxicity due to heavy metals, and the effects of cobalt, nickel, lead and manganese on the growth of tomatoes were investigated. Studies of the effect of soil conditions on the development of red-core disease of strawberries continued, while the Department of Genetics tested statistical methods devised for analysing continuous variation on the inheritance of flowering-time and plant-height in Nicotiana rustica. Investigations of the progress of inbreeding were started in Drosophila and rye.

The Department of Geology carried out work on natural and artificial glasses, with special reference to atomic packing, and considerable progress was reported in the design and construction of apparatus for work at temperatures up to $750^{\circ} \mathrm{C}$. and pressures of 1,000 atmospheres. In the Department of Mechanical Engineering research activities centred mainly on the investigation and application of the pressurewave phenomena which result from the sudden release of compressed gas, for example, from an engine cylinder, while in the Department of Civil Engineering two fundamental studies were made on the use of light alloys for large structures. Moment distribution methods for complex frames and space frames and the development of the beam-line method for solving problems on elastic and non-elastic frames were also studied. In the Department of Electrical Engineering several investigations on control systems, especially closed-sequence or servo-system type, were in progress, including contributions to theory, analysis and testing and the development of new devices. Earlier work on the mutual interference of radio waves in the ionosphere was being continued.

Research in the Department of Chemical Engineering was concerned mainly with liquid-vapour equilibria and their application to extractive distillation, combustion of hydrocarbons, chemical composition of coal tar, preparation and reactions of hydrocarbons and the diffusional factors concerned in mixing; also, work was started on pressure-volume-temperature relations of hydrocarbons under critical conditions, chemical compounds containing inorganic 